\title{
Understanding IAP function and regulation: a view from Drosophila
}

\author{
BA Hay ${ }^{\star, 1}$ \\ 1 Division of Biology, MC 156-29, California Institute of Technology, 1200 East \\ California Boulevard, Pasadena, CA 91125, USA \\ * Corresponding author: Division of Biology, MC 156-29, California Institute of \\ Technology, 1200 East California Boulevard, Pasadena, CA 91125, USA. \\ Tel: 626-395-3399; Fax: 626-449-0756; E-mail: haybruce@its.caltech.edu
}

Received 31.7.00; revised 20.8.00; accepted 23.8.00

Edited by S Kumar

\begin{abstract}
Apoptosis is an active form of cell suicide that results in the orderly death and phagocytosis of cells during normal development and in the adult. Many death signals lead to the activation of members of a family of cysteine proteases known as caspases. These proteins act to transduce death signals from different cellular compartments and they cleave a number of cellular proteins, leading ultimately to many of the biochemical and morphological events associated with death. Many mechanisms act to inhibit cell death upstream of caspase activation. However, only one family of cellular proteins, the inhibitors of apoptosis (IAPs), has been identified that inhibit caspase activation and/or activity. The observations that IAP function is essential for cell survival in Drosophila, and that IAP expression is deregulated in many forms of cancer in humans, argue that IAPs are important cell death inhibitors and that deregulation of their function is likely to be important in human disease. Here we review IAP function, with particular reference to insights that study of the Drosophila IAPs has provided. We also discuss some directions for future study. Cell Death and Differentiation (2000) 7, 1045-1056.
\end{abstract}

Keywords: caspase; IAP; inhibitor of apoptosis; Drosophila; Reaper; Hid

Abbreviations: IAP, inhibitor of apoptosis; CARD, caspase recruitment domain; BIR, baculovirus IAP repeat

\section{Discovery of the IAP family of cell death inhibitors}

In 1991 Lois Miller and colleagues described the identification of a baculovirus protein, p35, from the Autographa californica nucleopolyhedrovirus, that functioned to block lepidopteran host cell death in the context of viral infection. ${ }^{1}$ Over the years p35 has been shown to inhibit cell death in a variety of organisms, in many different contexts (reviewed in refer- ences $^{2,3}$ ). A mechanistic basis for this inhibition was provided when it was discovered that p35 acts as a broad specificity inhibitor of members of the caspase family of proteases, which act in many contexts as cell death signal transducers and executioners. ${ }^{4,5}$ Baculovirus genomes have acquired many genes from other genomes, presumably the host cellular genome or genomes of other viruses (reviewed in reference ${ }^{6}$ ). In Autographa californica, p35 occurs in a nonconserved region, suggesting that it came from another genome, perhaps its insect host. Recently a very divergent p35 homolog, SI-p49, was isolated from the Spodoptera littoralis nucleopolyhedrovirus (SINPV). ${ }^{7}$ A comparison of p35 and SI-p49 sequences identifies conserved regions that one might hope would provide the basis for identification of cellular p35 homologs. However, searches have thus far failed to identify such proteins, leaving the origins and extent of this family of caspase inhibitors unclear.

Following up on their identification of p35 as a baculovirus encoded cell death suppressor, Miller and colleagues carried out a screen to identify baculovirus proteins that could suppress the death of lepidopteran cells infected with a p35-deleted Autographa californica nuclear polyhedrosis virus (AcMNPV) baculoviral strain. Deathsuppressing genes from two different viruses, Cydia pomonella granulovirus (CpGV), and Orgyia pseudotsugata nucleopolyhedrovirus (OpNPV) were identified. ${ }^{8-10}$ The encoded proteins, Cp-IAP and Op-IAP, had no similarity with $\mathrm{p} 35$, but showed a high degree of similarity to each other, thus defining the first members of the inhibitor of apoptosis (IAP) family of proteins. These proteins contain two $\mathrm{N}$-terminal repeats of an $\sim 70$-amino acid motif known as a baculovirus IAP repeat (BIR). As discussed below, this motif plays an essential role in death inhibition by all IAPs. In addition, Op-IAP and Cp-IAP also contain a C-terminal RING finger domain. This domain is required for death inhibition of some, but not all IAPs. RING fingers have been found in proteins that function in a number of different contexts. For some of these proteins the RING domain confers ubiquitin ligase activity. ${ }^{11}$

Since the original identification of baculoviral IAPs, a number of cellular proteins have been identified in organisms ranging from yeast to humans that share similarity with the baculoviral IAPs, based on the presence of one or more copies of the BIR motif (reviewed in references $^{12-15}$ ) (Figure 1 ). A number of these BIR repeatcontaining proteins (BIRPs) have been shown to function as cell death inhibitors using various assays, usually overexpression. In mammals these include XIAP (MIHA, hILP), c-IAP1 (MIHB), c-IAP2 (MIHC), NAIP and Survivin (TIAP in the mouse) (reviewed in references ${ }^{13,15}$ ). DIAP1, DIAP2 and Deterin have been shown to act as cell death inhibitors in Drosophila. ${ }^{16,17}$ In addition, two different 

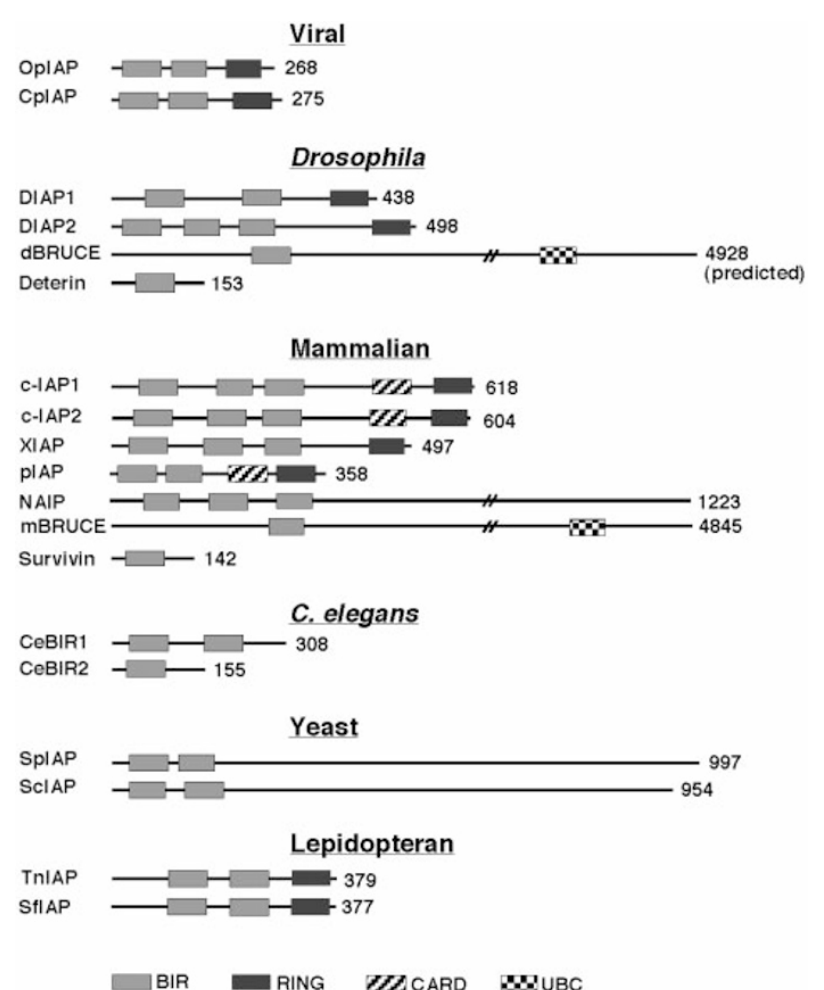

Figure 1 Schematic representation of selected BIR-containing proteins that inhibit cell death. The domains indicated by boxes are the BIR, RING, UBC, and CARD. Total protein amino acids lengths are indicated to the right. The baculoviral sequences are from Cydia pomonella granulovirus (Cp-IAP, P41436), and Orgyia pseudotsugata nucleopolyhedrovirus (Op-IAP, P41437). Accession numbers for the Drosophila sequences are: DIAP1, Q24306; DIAP2, Q24307; Deterin cDNA, A12600030; predicted dBRUCE, CG6303. The mammalian sequences are human (c-IAP1, Q13490; c-IAP2, Q13489; XIAP P98170; NAIP, AAC52047), mouse (mBRUCE, CAA76720), and pig (pIAP, AAc39171). Accession numbers for the $C$. elegans sequences are: CeBIR1, AAD00182; CeBIR2, AAB94330. Accession numbers for the lepidopteran IAPs are: SfIAP, AAF35285; Tn-IAP, AF195528. Accession numbers for the yeast BIRPs are SpIAP, CAA20434; ScIAP, AAB39312.1 The length of the Drosophila BRUCE homolog is not known. The sequence is predicted by Celera Genomics and can be found at the Berkeley Drosophila Genome website (http://www.fruitfly.org). Adapted from ${ }^{14}$

lepidopteran IAPs, SfIAP and Tn-IAP1, also inhibit cell death. ${ }^{18,19}$ The most convincing data arguing that IAPs normally function as cell death inhibitors comes from observations showing that the Drosophila IAP DIAP1 is required for the survival of many cell types in the fly. ${ }^{16,20-22}$ Interestingly, however, not all BIRPs function as cell death inhibitors. Some viral IAPs do not block death and their function is unknown (reviewed in reference ${ }^{23}$ ). BIRPS that do not (or are unlikely to) inhibit apoptosis have also been identified in $C$. elegans and yeast (reviewed in reference ${ }^{12}$ ). The $C$. elegans protein Bir-1 is required for cytokinesis. ${ }^{24}$ The Saccharomyces cerevisiae protein BIR1 is required for meiosis and mitosis, and the Schizosaccharomyces pombe gene Bir1p is required for chromosome segregation at the metaphase/anaphase transition. ${ }^{25-28}$ These proteins, as well as the mammalian cell death inhibiting BIRP Survivin, which also appears to play a role in cell cycle regulation, ${ }^{29,30}$ have BIRs that form a distinct structural subgroup. $^{12}$ Thus, while all members of the IAP family of cell death inhibitors contain one or more BIR repeats by definition, not all proteins with BIR repeats are IAPs.

\section{The Drosophila IAPs}

The Drosophila IAPs were among the first cellular IAPs isolated. Drosophila IAP1 (DIAP1), the product of the thread (th) locus, was identified from a genetic screen for cell death suppressors. ${ }^{16}$ Since this screen forms the basis for many of the assays used to characterize IAP function in the fly we describe the screen in some detail.

Many but not all apoptotic cell deaths in the fly require the functions of one or more of three genes, reaper $(r p r),{ }^{31}$ head involution defective (hid), ${ }^{32}$ and grim, ${ }^{33}$ located in the $75 \mathrm{C}$ region of the genome. These genes are transcriptionally or post-transcriptionally activated in many cells that die. The death they induce is inhibitable by p35 or tetrapeptide caspase inhibitors, and is thus caspase-dependent. ${ }^{16,32-35}$ In addition, overexpression of any one of these genes is sufficient to induce caspase-dependent death in many cells that normally live (reviewed in references ${ }^{36,37}$ ).

The Drosophila eye has proved to be a good system in which to screen for genes important in a number of cellular processes. ${ }^{38}$ It is particularly well suited for the study of cell death because the eye is nonessential for viability or fertility. Thus increased eye cell death can be scored as viable flies that have small eyes. Finally, proteins can be expressed specifically in the eye using the $\mathrm{P}$ element transposon vector GMR. ${ }^{39}$ Expression of rpr, hid or grim in the eye using the GMR vector (e.g. GMR-rpr flies) leads to increased retinal cell death, which manifests itself as flies with small eyes (Figure 2). These flies, in which cell death signaling has been hyperactivated, constitute a sensitized genetic background. In this background a twofold reduction (making the fly heterozygous for a loss-of-function mutation) in the activity of other genes in the activated death pathway may result in a change in eye phenotype. For example, dominant suppressors of the small eye phenotype may identify genes required to carry out cell death, while dominant enhancers may identify genes that normally act to antagonize cell death signaling. Thus, for screening purposes, one can often think of the eye as a living 96 well plate in which the level of cell death signaling is read out as a function of change in eye size.

It is important to note, however, that a dominant modifier screen such as that described above is limited to identifying death regulators from among the subset of genes that are expressed in the eye, and that are rate limiting for the hyperactivated pathway. To identify death regulators that normally function in other tissues, in an eye-based screen, a different approach must be used. One strategy that may often work involves screening for modifiers that result from targeted eye-specific gene overepression using a transposon mutagen that carries an eye-specific enhancer. ${ }^{40}$

We screened a collection of deficiencies that uncovers about $70 \%$ of the genome for dominant enhancers and suppressors of GMR-rpr- and GMR-hid-dependent cell death, and identified one region, at $72 \mathrm{D}$, that acted as a very strong enhancer (Figure 2). Lethal mutations in the 


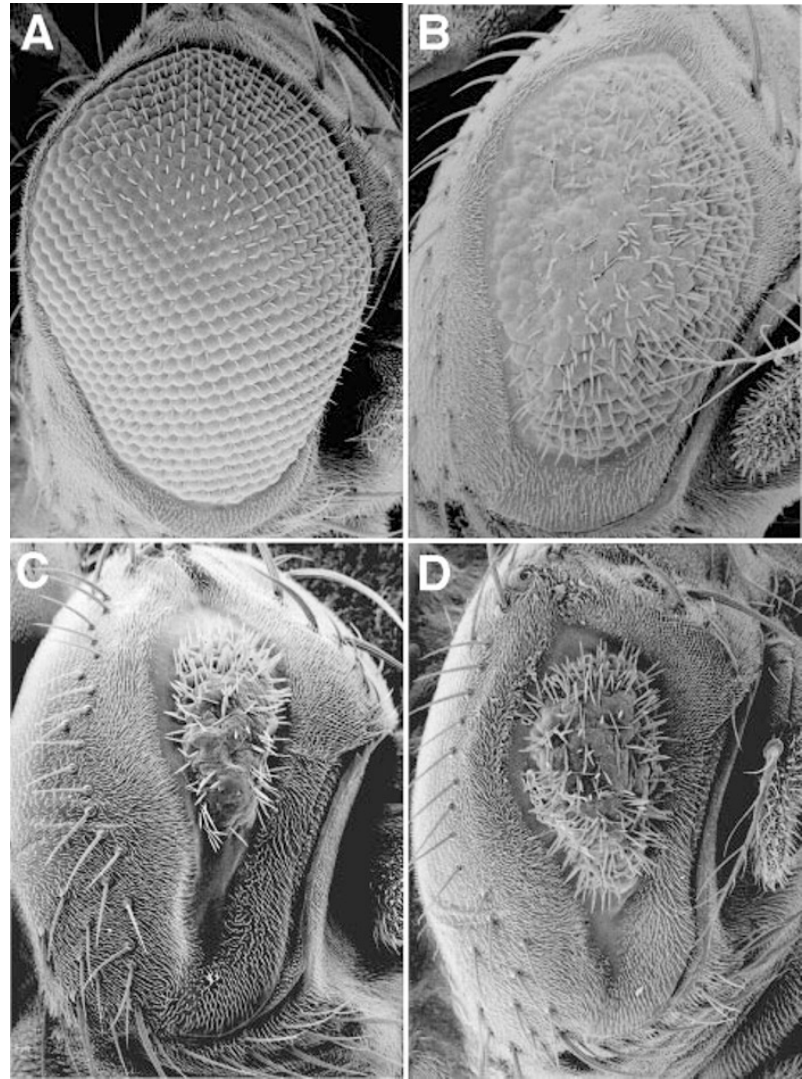

Figure 2 Fly eye phenotypes associated with expression of $r p r$ in the fly eye in wild-type and DIAP1 loss of function mutant backgrounds. The genotypes shown are wildtype (A); GMR-rpr/+ (B); GMR-rpr/+, Df Brm11/+ (C); GMR-rprl ,+ th5/+ (D). Wild-type flies have large eyes in which the unit eyes, the ommatidia, are highly ordered (A). The eyes of flies that overexpress rpr are small, and the organization of the ommatidia is disrupted (B). Reducing the levels of endogenous DIAP1 in flies that carry the GMR-rpr transgene using a deficiency that removes the th locus, Df Brm11, results in a strong enhancement of the GMR-rpr small eye phenotype (C). Introduction into the GMR-rpr background of the th5 mutation, which truncates DIAP1 within the second BIR domain, results in a similar small eye enhancer phenotype. Adapted from ${ }^{16}$

thread (th) locus, which also maps to this region, showed a similar phenotype (Figure 2). Cloning of thread showed that it encoded a protein, DIAP1, with a high degree of similarity to the viral IAPs, in that it contained two N-terminal BIR repeats and a C-terminal RING finger. ${ }^{16} \mathrm{~A}$ number of DIAP1 mutants have also been isolated more recently in dominant modifier screens for enhancers and suppressors of GMR-rpr-, GMR-hid-, and GMR-grim-dependent cell death. ${ }^{21,22}$ We and others also identified a second Drosophila IAP, referred to here as DIAP2, that has three N-terminal BIR repeats and a C-terminal RING finger. ${ }^{16,41-43}$ The th locus and hid were also identified in a later eye-based gene overexpression screen for cell death regulators. ${ }^{40}$

DIAP1 blocks normally occurring cell death in the fly eye, ${ }^{16}$ as well as that induced by GMR-driven expression of rpr, hid ${ }^{16,21,22,44,45}$ or grim. $^{22}$ DIAP2 overexpression also results in suppression of these deaths, ${ }^{16,44}$ though results with respect to grim depend on the expression system
(Vernooy and Hay unpublished, GMR-grim, yes; ${ }^{44}$, GMRGAL4-UAS grim, no). More recent observations have shown that DIAP1 and DIAP2 can inhibit cell death in response to a variety of stimuli in lepidopteran cells, ${ }^{46-50}$ and in mammalian cell culture. ${ }^{51}$

It was observed early on that fragments of DIAP1 and DIAP2 consisting of the BIR repeats, but lacking the RING finger, retained the ability to inhibit a number of different cell deaths. ${ }^{16}$ These observations provided the first evidence that the DIAP1 BIR repeats alone were sufficient to inhibit cell death. For DIAP1, the BIR repeats without the RING provided greater protection from several different death stimuli in the fly eye (X-ray irradiation and GMR-hid) than did the full-length protein. This, in conjunction with the observation that expression of the RING domain in isolation induced retinal cell death, suggested that the RING domain might negatively regulate in some way DIAP1's BIRdependent death inhibition function. More recent observations in lepidopteran cells confirm that the BIR repeats alone are better death protectors than the full length protein with respect to $\mathrm{hid}^{49,50}$ and that expression of the RING alone promotes cell death. ${ }^{46}$ However, in other contexts the DIAP1 BIR repeats protect less well than the full length protein. ${ }^{46,47}$ Together, these results suggest that DIAP1 and DIAP2 inhibit cell death through multiple mechanisms. These are discussed in more detail below.

Overexpression of DIAP1 or DIAP2 is sufficient to block cell death in the fly, but do these proteins normally perform this function? In the case of DIAP1 the answer is very clearly yes. DIAP1 is expressed at high levels throughout embryogenesis ${ }^{16}$ and in a number of other tissues, including the eye $\mathrm{e}^{22}$ and ovary. ${ }^{52}$ Expression in many other tissues has simply not been examined. Decreasing the dose of DIAP1 by twofold in the eye increases rpr-, hid-, and grim-dependent cell death, indicating that the endogenous levels of DIAP1 are sufficient to act as a brake on induced death. Most striking, however, are observations of cells homozygous for DIAP1 loss-offunction mutations. Early observations that clones of DIAP1 mutant cells could not be obtained suggested that DIAP1 was required for the survival of cells in the eye and ovary. $^{16}$ More recent observations showed that zygotic DIAP1 expression is in fact required for the survival of probably all cells in the embryo. ${ }^{20-22}$ Together, these observations suggest that, at least during development, DIAP1 function, or perhaps that of DIAP2 in certain cases, ${ }^{53}$ is required for the survival of all cells. In lepidopteran cells, overexpressed DIAP1 and DIAP2 are localized in a punctate cytoplasmic pattern. ${ }^{48,49}$ What these sites are, and their physiological significance, is unknown.

The normal functions of DIAP2 are more enigmatic. DIAP2 blocks cell death due to overexpression of $r p r$, hid or grim very efficiently when overexpressed in the eye or in lepidopteran cells, yet deficiencies that remove this locus have no effect on GMR-rpr- or GMR-hid-dependent retinal cell death. ${ }^{16}$ This suggests that DIAP2 is either not expressed in the fly eye (and thus twofold reductions in its genetic dose have no consequence) or that its activity is not rate limiting, perhaps due to a large excess of DIAP1. Alternatively, endogenous DIAP2 may have other preferred 
targets. The most notable feature of DIAP2 expression described thus far is that it is transcriptionally regulated as part of a coordinated, ecdysone-dependent response that leads to cell death of the larval salivary gland. ${ }^{53}$ DIAP1 and DIAP2 transcription are also regulated during ovarian development and the death of the germline nurse cells. ${ }^{52}$

Two other proteins with BIR repeats have recently been identified in Drosophila. Deterin is a small protein with a single $\mathrm{N}$-terminal $\mathrm{BIR}$ repeat and a $\mathrm{C}$-terminal region that may form a coiled coil. ${ }^{17}$ It is most similar in overall structure, and within the BIR repeat, to mammalian Survivin. Deterin has been shown to block rpr-dependent cell death, as well as death due to the act of cell transfection in a Drosophila cell culture system. The contexts in which Deterin functions in the fly remain to be determined. $\mathrm{dBRUCE}^{14}$ is a predicted protein homolog of mammalian BRUCE. ${ }^{54}$ BRUCE and dBRUCE are intriguing, if somewhat daunting proteins. They are most notable for their size (predicted to be greater than $500 \mathrm{kD}$ ), and the fact that they each have an N-terminal BIR repeat and a $\mathrm{C}$ terminal domain that is predicted to have E2 ubiquitin conjugation activity. In the case of BRUCE this activity has been demonstrated. ${ }^{54}$ The dBRUCE BIR repeat is noteworthy because it is much more similar to the BIR repeat of its mammalian counterpart than the BIR repeats of other evolutionarily distant IAPs are to each other. As of yet there is no evidence linking BRUCE or dBRUCE function to cell death regulation.

\section{IAPs as caspase inhibitors}

Mammalian IAPS Most if not all cells express caspases sufficient to carry out apoptosis. Since proteolytic activation is irreversible, and caspases have the ability to engage in amplifying cascades of proteolysis, their activation and activity must presumably be tightly inhibited in cells that normally live. IAPs have been shown to interact with a number of different proteins (reviewed in references ${ }^{13,15}$ ). A mechanism by which a number of these might function to inhibit cell death was originally suggested by the observations that several mammalian IAPs inhibit caspase activation or activity. XIAP, c-IAP1 and c-IAP2 bind and inhibit the activation of the apical caspase caspase-9. In addition they also inhibit active forms of caspases 3 and 7, including an intermediate form in which the large subunit still contains the prodomain and a C-terminal linker that forms the junction between large and small subunits. ${ }^{55-58}$ XIAP, C-IAP1, and cIAP2 appear not to interact with caspases-1, -6, -8 or -10. NAIP inhibits cell death in some contexts, ${ }^{42,59,60}$ but it has not been shown to interact with any caspases. It is possible the NAIP caspase partner has not been identified or tested. It has recently been suggested that NAIP mediates at least some of its death protective effects through interactions with Hippocalcin, a calcium-binding protein that it binds through the third NAIP BIR. ${ }^{61}$ Several mammalian IAPs, including $\mathrm{C}$ IAP1, C-IAP2 and pIAP have CARD domains (Figure 1). The significance of these for caspase inhibition is unclear since XIAP, which inhibits multiple caspases, lacks a CARD. Perhaps the IAP CARD mediates interactions with other apoptotic regulators that have CARD domains (reviewed in reference ${ }^{62}$ ).

Survivin inhibits caspase-dependent cell death in a number of contexts (reviewed in references ${ }^{13,15,63}$ ), and has been immunoprecipitated from cells or reticulocyte lysates in association with active caspase-3 and $-7 .^{64,65}$ More recently, others have failed to observe interactions between recombinant Survivin and caspase-3, or any ability of Survivin to inhibit caspase-3. ${ }^{66}$ However, these latter observations leave open the possibility that Survivin in vivo is modified in ways that promote its function as a caspase inhibitor (c.f. reference ${ }^{67}$ ). Other models of Survivin function are presented in the discussion of Deterin function (below).

Drosophila IAPs Drosophila encodes 7 functional caspases and there is ample evidence that cell death in Drosophila is caspase-dependent (reviewed in reference ${ }^{14}$, Kumar et al, this issue). Of the four Drosophila BIRPs, only DIAP1 has been shown to inhibit caspase activity. DIAP1 inhibits the death of yeast that express full length DCP-1, ${ }^{68}$ a constitutively activated form of drICE in which the large and small subunits are rearranged into an active conformation, ${ }^{20}$ or full length DRONC. ${ }^{69}$ Since yeast lack a described apoptotic pathway, it seems likely that DIAP1's ability to inhibit caspase-dependent yeast cell death is due to its function as a caspase inhibitor. Supporting this argument, recombinant DIAP1 has also been shown to inhibit the caspase activity of recombinant DCP-1, ${ }^{68}$ as well as the activity of three other Drosophila caspases, DECAY, DREAM and DAYDREAM (SJ Yoo, unpublished) in in vitro assays. In addition, DIAP1 has been shown to bind to certain forms of drICE in cell extracts, ${ }^{47}$ and to interact with the DRONC prodomain, as well as processed forms of DRONC. ${ }^{70}$ Together, these results suggest that DIAP1 may be able to inhibit the activation or activity of all Drosophila caspases. However, as discussed below in the section on IAPs as ubiquitin-protein ligases, it is important to keep in mind that in vivo IAPs may inhibit caspase activity through multiple mechanisms. Interactions between DIAP2 and Drosophila caspases, including DCP-1, drICE and DRONC, have not been detected (CJ Hawkins, unpublished).

The best evidence supporting the idea that DIAP1 has a prosurvival function in vivo as a caspase inhibitor comes from the observation that DIAP1 mutant embryos, in which all cells die, have greatly increased levels of caspase activity that is DIAP1 inhibitable. ${ }^{20}$ In addition, DIAP1 has also been shown to block DRONC-dependent cell death in the fly eye, ${ }^{69,70}$ and drICE-, Sf-caspase-1- and mammalian caspase-3-dependent lepidopteran cell death. ${ }^{47}$

What are DIAP1's caspase targets in vivo? In addressing this question it is useful to include observations made in lepidopteran cells as well. The Drosophila caspase field is still at a very early stage, and possible pathways of caspase activation are only just being identified (reviewed in Kumar et al, this volume). In one major pathway of caspase activation in mammals, cellular stress of various sorts leads to the release of mitochondrial cytochrome-c, which binds the cytosolic adaptor protein Apaf-1. Cytochrome-c-bound Apaf-1 binds to and activates caspase-9. CARD domains present in Apaf- 1 and caspase- 9 mediate 
interactions between the two proteins (reviewed in reference ${ }^{71}$ ). DRONC is likely to be the Drosophila caspase-9 ortholog because it is the only Drosophila caspase with a CARD domain, ${ }^{72}$ and it binds the Drosophila Apaf-1. ${ }^{73}$ The fact that dominant negative forms of DRONC inhibit rpr-, hid-, and grim-dependent cell deaths in the fly argues, though not definitively, that DRONC is an important apical cell death caspase acting downstream of these genes. ${ }^{69,70}$ DRONC has several unusual features. Unlike other caspases, it cleaves after glutamate as well as aspartate. ${ }^{69}$ In addition, it is p35insensitive. ${ }^{69,70}$ Cell death induced in lepidopteran cells by viral infection or actinomycin $D$ also involves a p35insensitive proteolytic event. ${ }^{74-76}$ The caspase that mediates this cleavage is unknown. Active versions of DRONC and the DRONC-like lepidopteran caspase presumably process and activate effector caspases with short prodomains. Based on patterns of caspase cleavage observed in vitro, ${ }^{69,70}$ and in lepidopteran cells, ${ }^{75,76}$ drICE and Sf-caspase-1 are good candidates, respectively. Other insect short prodomain caspases have not been tested.

An important site of DIAP1 prosurvival function is likely to be inhibition of the p35-insensitive apical caspase. DIAP1 inhibits GMR-DRONC-dependent retinal cell death. ${ }^{69,70}$ Since DIAP1 binds the DRONC prodomain and inhibits DRONC-dependent killing of yeast, it seems likely that DIAP1's effects on DRONC activity in vivo are direct. These observations, together with those showing that dominant negative DRONC blocks cell death in flies, suggest that inhibition of DRONC activation and/or activity is likely to be an important DIAP1 prosurvival function. The steps at which DIAP1 acts to inhibit DRONC function are unknown. The baculovirus IAPs Op-IAP and Cp-IAP also act on a p35-insensitive apical caspase, perhaps a DRONC-like caspase-9 homolog. Thus, Op-IAP and CpIAP block the activating cleavage of Sf-caspase-1 between the large and small subunits in lepidopteran cells, while p35 fails to do so. ${ }^{75,76}$ In addition, the lepidopteran IAP, SfIAP, has been shown to inhibit the activation of caspase-9 in mammalian cells, but shows no activity towards the effector caspases caspase-3 and caspase-7. ${ }^{18}$ While SfIAP's activity with respect to inhibition of Sf-caspase-1 activation has not been tested, these results suggest that it (and presumably also the closely related lepidopteran IAP TnIAP1) inhibits the lepidopteran caspase-9 homolog.

DIAP1 may also inhibit the activity of Drosophila caspases activated by DRONC, or by other long prodomain caspases such as DCP-2/DREDD or DREAM. This point is suggested in Drosophila by the fact that DIAP1 inhibits the activity of many Drosophila caspases in vitro. It is also suggested by the fact that in lepidopteran cells DIAP1 binds to an active (large-small subunit cleaved) version of drICE generated when the full-length drICE coding region is introduced into cells experiencing a death signal. Interestingly however, DIAP1 does not bind either the full length drICE precursor or active drICE resulting from the introduction into cells of plasmids that express mature large and small subunits. ${ }^{47}$ These observations suggest that in vivo DIAP1 inhibits the activity of a drICE processing intermediate. Consistent with this hypothesis, we observed that versions of drICE that lack prodomain sequences are not inhibited by DIAP $1,{ }^{68}$ while versions that contain these sequences are inhibited. ${ }^{20}$

The fact that DIAP1 is unable to inhibit cell death induced by prodomainless GMR-DRONC, or the activity of fully mature drICE, indicates that there are points at which caspase signaling and effector function can be made independent of DIAP1 activity. It will be interesting to see if the cleavage events that generate these DIAP1insensitive caspases define points of cell death regulation in vivo.

\section{Functional interactions between DIAPs, Reaper, Hid and Grim and caspases}

Death-inhibiting IAPs have been shown to bind a number of different cellular proteins other than caspases (reviewed in reference ${ }^{13,15}$ ). Some of these may identify mechanisms by which IAPs inhibit apoptosis, or by which IAP activity is regulated. Others may point towards roles of IAPs in signal transduction. Here we focus on the Drosophila IAP interacting proteins, Reaper, Hid and Grim, and the mammalian protein Smac/Diablo, because the functions of these proteins are clearly linked to regulation of cell death. Interactions of Drosophila IAPs with Doom, a Drosophila-derived apoptosis inducer that binds baculovirus IAPs, ${ }^{77}$ and with the Thick Veins receptor, ${ }^{78}$ are not discussed.

Reaper, Hid and Grim promote caspase-dependent cell death, and they each contain a short region (about 15 amino acids) of homology at their $\mathrm{N}$-termini. This sequence is sufficient to allow binding to DIAP1 and DIAP2. ${ }^{48,49}$ These sequences also mediate Reaper and Grim binding to c-IAP1 from mammals. ${ }^{79}$ Domain analysis of Hid and Grim indicates that the presence of these $\mathrm{N}$-terminal sequences on proteins is sufficient to induce apoptosis in lepidopteran cells. ${ }^{49}$ These observations suggested a model in which Reaper, Hid and Grim promote apoptosis by inhibiting DIAP1 function as a caspase inhibitor, thereby unleashing latent caspase activity (Figure 3$).{ }^{47}$ Several observations

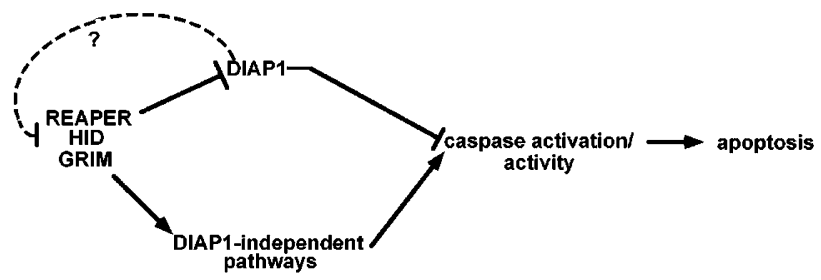

Figure 3 Several pathways by which DIAP1 may regulate cell death in Drosophila. DIAP1 inhibits caspase activation and/or activity. Reaper Hid and Grim promote cell death by binding to DIAP1, inhibiting this activity. Reaper, Hid and Grim can block DIAP1 function as a caspase inhibitor directly. In vivo they may also regulate DIAP1 function in other ways, perhaps by regulating a DIAP1-associated ubiquitin protein ligase activity. In this pathway free DIAP1 inhibits cell death by binding and titrating Reaper, Hid and Grim away from DIAP1-caspase complexes, and by inhibiting caspase activation or activity. Reaper, Hid and Grim may also promote caspase activation through DIAP1independent pathways. The binding of free DIAP1 to these proteins may inhibit their ability to act through these other pathways. The hypothetical nature of this pathway is indicated by the broken line and the question mark. Thus DIAP1 may act to inhibit Reaper, Hid and Grim activity, as well as the consequences of their activation 
strongly support this model. First and foremost, in in vitro assays containing purified DIAP1 and DCP-1, full length Hid or an N-terminal cell killing Hid fragment are able to block DIAP1's ability to inhibit caspase activity. ${ }^{20}$ Reaper and Grim, Hid and the N-terminal cell killing Hid fragment also block DIAP1's ability to inhibit caspase-dependent yeast cell death. Finally, a peptide corresponding to the first 18 residues of Grim prevents the lepidopteran IAP SfIAP from inhibiting the activation of downstream caspases in a mammalian cell extract system. ${ }^{18}$ These observations all argue that Reaper, Hid and Grim can block DIAP1 and SflAP function as caspase inhibitors. But do they perform this function in vivo? Reaper, Hid and Grim can induce the death of cells that normally live. If inhibition of DIAP1 constitutes a primary mechanism by which these genes act, then loss of DIAP1 in cells that normally live should lead to a similar phenotype: cell death associated with increased caspase activity. As discussed above, at least in the embryo this is in fact the case. ${ }^{20}$ Finally, this model predicts that versions of DIAP1 that do not bind Reaper, Hid or Grim should be relatively insensitive to the death-promoting activity of these proteins. Such mutants should be identified in eye-based dominant modifier screen as death suppressors. Several such mutants have in fact been identified. ${ }^{21}$ While it is possible that these mutant proteins are simply better caspase inhibitors than the wildtype DIAP1, these results are consistent with the idea that the mutant DIAP1 proteins are more potent suppressors of $r p r$ and grim-dependent cell death because they interact with these proteins less well.

Apoptotic cell death is an evolutionarily old process. Thus it is expected that molecules and mechanisms of cell death regulation found in one group of organisms may be present in others as well. Recent observation suggest that this is true as well for regulation of productive IAP-caspase interactions. Thus, several groups recently identified a protein known as Smac, ${ }^{80}$ or DIABLO, ${ }^{81}$ that binds a number of different mammalian and baculoviral IAPS. Smac/Diablo is initially localized to mitochondria. Following an apoptotic stimulus it is released into the cytoplasm along with cytochrome $\mathrm{c}$, where it binds IAPs. In addition, overexpression of Smac/Diablo sensitizes cells to different apoptotic stimuli. These observations argue strongly that Smac/Diablo, like Reaper, Hid and Grim, suppresses IAP function. How Smac/Diablo achieves this is unclear, but the observation that Smac/DIABLO, like Reaper, Hid and Grim, inhibits the ability of IAPs to block caspase-dependent yeast cell death, suggests their mechanism(s) of action may be similar. $^{81}$ (See Note added in proof.) The identification of Smac/Diablo leaves open the possibility that there are additional mammalian proteins that inhibit IAP function. There are several reasons to consider this. First, Smac/Diablo has a restricted tissue distribution. Second, Smac/Diablo is localized to mitochondria. From this site it is expected to promote apoptosis as a part of the caspase- 9 activation cascade, inhibiting IAP functions that would antagonize cytochrome- $c$ and Apaf-1-dependent caspase- 9 activation. However, it seems very reasonable to imagine that there will exist other, perhaps cytoplasmic proteins that perform a similar function in the context of other signal transduction pathways that regulate cell death. Hid orthologs are a particularly attractive possibility since Hid is regulated both transcriptionally ${ }^{82}$ and post-transcriptionally ${ }^{45}$ by the Ras/Map kinase pathway, which plays many roles in regulating decisions of cell fate and survival.

The above observations suggest that overexpression of DIAP1 inhibits cell death through several mechanisms: by acting as a sink for Reaper, Hid and Grim, titrating them away from interactions with DIAP1 bound to caspase, and by directly inhibiting caspase activation or activity. DIAP1 binding to Reaper, Hid and Grim may also serve to inhibit other proapoptotic functions of these proteins (Figure 3). Peptides corresponding to the N-termini of Reaper and Grim have been shown to inhibit the activation of potassium channels. ${ }^{83}$ This might promote depolarization-dependent cell death. Binding of Reaper, Hid or Grim to cytoplasmic DIAP1 via their $\mathrm{N}$-terminal sequences might be expected to prevent functional interactions of these same sequences with membrane channel proteins. Reaper, Hid and Grim also interact in a Xenopus extract system with the Scythe protein. ${ }^{84}$ These interactions do not require the conserved Reaper, Hid, Grim N-terminal sequences. In the case of at least Reaper, binding to Scythe is associated with release of a cytoplasmic factor that promotes the release of cytochrome c from mitochondria. Drosophila has a Scythe homolog, ${ }^{14}$ suggesting that one or more of Reaper, Hid or Grim may promote apoptosis through a Scythe-dependent pathway. At this point it is unclear if binding of Reaper, Hid or Grim to DIAP1 prevents productive interactions with Scythe. However, as discussed below, the observation that RING finger-containing IAPs can have ubiquitin ligase activity towards bound substrates suggests another mechanism by which DIAP1 or DIAP2 might inhibit Reaper-, Hid- or Grim-dependent cell death: by promoting their ubiquitination and degradation.

\section{IAPs as ubiquitin-protein ligases}

Many proteins are modified by the covalent attachment of one or more copies of ubiquitin, a 76-amino acid protein. In many cases ubiquitination leads to subsequent degradation of the modified protein by the $26 \mathrm{~S}$ proteosome (reviewed in reference ${ }^{85}$ ). Attachment of ubiquitin to a substrate typically involves the action of three enzymes, a ubiquitin activating enzyme (E1), a ubiquitin carrier protein (E2), and a ubiquitinprotein ligase (E3). Free ubiquitin is bound to $E 1$ by a thioester bond. This activated ubiquitin is then transferred to E2 through a second thioester bond formed between ubiquitin and E2. In a third step, E2, in conjunction with substrate bound E3, transfers ubiquitin to target proteins. There is one $E 1$, but there are many E2s, E3s or E3 multiprotein complexes. Recently it has been recognized that RING fingers of a number of different proteins have E3 ubiquitin-protein ligase activity (reviewed in references ${ }^{11,86}$ ). Several IAPs, C-IAP1 and XIAP, are among these. Thus, in the presence of E1 and E2, C-IAP1 and XIAP are able in vitro to catalyze autoubiquitination. In addition, deletion or mutation of the RING suppresses IAP ubiquitination and degradation in vivo. Intriguingly, full length, but not RING mutated versions of these IAPs disappear in thymocytes induced to die, 
suggesting that stimulation of IAP auto-ubiquitination defines a mechanism for promoting cell death. ${ }^{87}$ The nature of the signals that promote IAP auto-ubiquitination in thymocytes are unknown. C-IAP1 has also recently been shown to monoubiquitinate caspase- 3 and caspase- 7 in vitro. ${ }^{88}$ The physiological significance of this reaction is unclear, but it does suggest the possibility that RING-containing IAPs may ubiquitinate and promote the degradation of bound proapoptotic substrates. This would provide a mechanism whereby IAPs could inhibit the activity of apoptosis inducers catalytically, rather than stoichometrically.

At this point it is not known if DIAP1 has E3 activity. But it seems likely that it does. There are several nonexclusive models for how RING-dependent ubiquitin ligase activity might regulate DIAP1 function. One possibility is that RINGdependent DIAP1 auto-ubiquitination, as with C-IAP1 and XIAP, promotes DIAP1 degradation. Stimuli that promote this activity would then have the effect of decreasing IAP levels, thus sensitizing cells to lower levels of inducers or caspase activity. What might define an auto-ubiquitinationpromoting stimulus? Perhaps Reaper, Hid or Grim binding to DIAP1. DIAP1 E3 activity might also promote the degradation of bound apoptosis inducers such as Reaper, Hid, Grim or caspases. In this model IAP ubiquitin ligase activity would promote DIAP1's prosurvival function. In the context of this hypothesis it is interesting to note that in lepidopteran cells expression of Op-IAP or Cp-IAP is associated with the formation of a ladder of higher molecular weight forms of Reaper and Hid. ${ }^{48,49}$ Finally, in a substrate choice model DIAP1 may have both activities. DIAP1 might, for example auto-ubiquitinate itself when it is free, but preferentially ubiquitinate other substrates when they are DIAP1-bound. In this way DIAP1 levels would be regulated according to the cell's current levels of proapoptotic DIAP1-interacting proteins. Stimuli that alter the ratio of cis to trans ubiquitination would promote or suppress apoptosis, respectively. These models are all speculative, but they are also eminently testable.

\section{Deterin cell death while Survivin the cell cycle}

The small, single BIR mammalian IAP Survivin has excited much interest recently because its transcription is upregulated in many human cancers. ${ }^{89}$ In normal cells Survivin expression is upregulated in $\mathrm{G} 2 / \mathrm{M}$, and it is essentially absent in postmitotic cells. Survivin inhibits cell death in culture in response to a number of different stimuli, including expression of caspases. In addition, antisense Survivin promotes caspase activity and cell death (reviewed in reference ${ }^{13}$ ). Finally, as noted above, Survivin has been found by some, but not others, to bind directly to caspases. Thus, Survivin is a tumor marker, and potentially a good therapeutic cancer target since it is not appreciably expressed in normal post mitotic cells. However, there is also good evidence that Survivin may not function only as a cell death inhibitor (reviewed in reference ${ }^{63}$ ). The Survivin BIR repeat is most closely related to those found in BIRPs of $C$. elegans, $S$. cerevisiae and $S$. pombe. Genetic analysis indicates that these proteins promote cytokinesis and chromosome segregation. The $C$. elgans protein BIR1 does not inhibit cell death, ${ }^{24}$ and it seems unlikely that the yeast proteins do either. Survivin can partly rescue the $C$. elegans cytokinesis defect in bir1 mutants, suggesting some conservation in function. Survivin also localizes to the mitotic spindle in anaphase,$^{30}$ as does the $S$. cerevisiae protein Bir $1 p .{ }^{25}$ Finally, loss of Survivin function leads to a number of cell division defects, including hyperploidy, multinucleation, and extra centrosomes, all consistent with defects in cytokinesis. ${ }^{30}$

A domain analysis of Survivin indicates that it localizes to spindle microtubules via interactions with its C-terminal coiled-coil domain. The importance of this localization is suggested by the fact that deletion of the coiled-coil domain leads to a loss of antiapoptotic function in at least some contexts. Mutation of the BIR domain also leads to a loss of antiapoptotic function, and creates a molecule that has dominant negative activity, in that its expression promotes cell death and displaces wild-type Survivin away from spindles. $^{29}$

How is Survivin regulating cell death? One possibility is that caspase activity occurs as a normal part of the cell cycle, and that Survivin functions to regulate this activity. This caspase activity might be required for some aspect of cell division. Other observations suggest that Survivin might regulate caspase activity indirectly. Survivin has been described as translocating to the nucleus in response to some death signals, there binding the cyclin-dependent kinase 4 (CDK4). ${ }^{90}$ CDK4 itself can bind the CDK inhibitor, p21. p21 has been shown to have antiapoptotic activity in a number of systems (reviewed in reference ${ }^{91}$ ). While at least some of this activity may derive from p21's ability to inhibit proapoptotic activities associated with inappropriate CDK activation, p21 has also been described as an inhibitor of the activation of mitochondrially localized procaspase-3.92 Based on these observations it has been argued that Survivin might promote survival by promoting the release of p21 from CDK4. Survivin may also play a checkpoint role in monitoring the status of spindle assembly. In this model, defective spindle assembly would lead to delocalization of Survivin from microtubules, and thus loss of its ability to inhibit caspase activity. The fact that a fraction of caspase3 is localized to centrosomes (where Survivin is also present) in a Survivin-dependent manner supports this possibility. ${ }^{30}$ Alternatively, or in addition, Survivin may be an essential part of the machinery that carries out cell division. In this model, loss of Survivin function leads to cell cycle defects that indirectly promote caspase activation.

There are a number of important unanswered questions. Survivin is clearly able to inhibit cell death. Thus far this activity has only been shown in cycling cells in culture. Does it have activity in noncycling cells, or is it active in only one part of the cell cycle? What are the proteins Survivin interacts with that mediate its localization to spindles and centrosomes? Is caspase activation necessary for cell cycle progression? What is the source of the caspase activity found in cells with decreased Survivin function? Is it the result of loss of Survivin the caspase inhibitor or a secondary consequence of Survivin-dependent cell cycle defects? Drosophila provides a convenient system in which to address these questions. But is Drosophila Deterin a Survivin homolog? Several observations suggest that it may 
be. In early and mid embryogenesis Deterin mRNA expression shows no correlation with cell proliferation. However, somewhat later Deterin becomes upregulated in the developing gonad, a proliferative tissue. Survivin expression in other proliferative tissues, in particular the imaginal discs, has not been examined. The subcellular localization of the Deterin protein has also not been examined. However, Deterin clearly functions as a cell death inhibitor, at least in cells in culture. In addition, a domain analysis of Deterin suggests that, like Survivin, both the $\mathrm{N}$-terminal BIR domain and the $\mathrm{C}$-terminal domain are required for optimal function, and that mutation or removal of the BIR leads to the creation of a protein with dominant negative activity. Thus far, all manipulations of Survivin and Deterin function have been carried out in cell culture. However, ultimately it is important to examine the function of these proteins in cells functioning as a part of a tissue. Overexpression of the wild-type Deterin protein and the dominant negative version, as well as the use of RNAi knockout technology, should lead very quickly to an understanding of the consequences of manipulating Deterin levels in the fly. A characterization of these phenotypes in the presence and absence of caspase inhibitors should be very illuminating in uncovering roles Deterin plays as a cell cycle regulator and as a cell death inhibitor.

\section{Structure-function analysis of the mammalian IAPs}

The sequence requirements for caspase inhibition have been explored in mammals for XIAP and c-IAP1. Full length XIAP and C-IAP1 and C-IAP2 inhibit caspase-3 and caspase-7, and the activation of caspase-9.95-57 A fragment consisting of
BIR2 and about 30 residues $\mathrm{N}$ - and C-terminal (R124-P260) is sufficient for this activity. ${ }^{93}$ Inhibition of caspase- 9 activation by XIAP requires both BIR3 as well as the RING finger (A243end). ${ }^{58}$ Since the caspase activity assays used do not support RING-dependent ubiquitination, the RING must play a binding or structural role in this context. A short sequence $\mathrm{N}$-terminal to BIR2 (E134-Y154) plays a critical role in XIAP-dependent caspase inhibition. ${ }^{94}$ This $\mathrm{N}$-terminal extension contains a potential caspase target site (DISD), the P4 aspartate of which is required for BIR2-dependent caspase inhibition (Figure 4). Several lines of evidence suggest a model in which this fragment binds caspase- 3 in the active site (presumably via the DISD residues), perhaps in conjunction with a lower affinity caspase binding interaction mediated by the BIR domain. However, this simple interpretation is complicated by the fact that mutation of the putative P1 aspartate in the DISD sequence to alanine (DISA) causes only a threefold decrease in activity as a caspase inhibitor. In addition, the $\mathrm{P} 1$ aspartate is not conserved in other IAPs, leaving the generality of the proposed mechanism unclear. A number of other IAPs, including DIAP1, Op-IAP, Cp-IAP and DIAP2, have a conserved aspartate just $\mathrm{N}$-terminal to the BIR (DIAP1 D40). However, the significance of this aspartate or others nearby in the linker region has not been tested. An NMR structural analysis of a fragment of c-IAP1 consisting of BIR3 and a C-terminal linker has suggested that a conserved aspartate (D302) positioned within a BIR surface loop might also mediate interactions with caspases. ${ }^{95}$

Insect and viral IAPs It has been clear for some time that while insect and baculoviral IAP have prosurvival functions as caspase inhibitors, they also have important functional

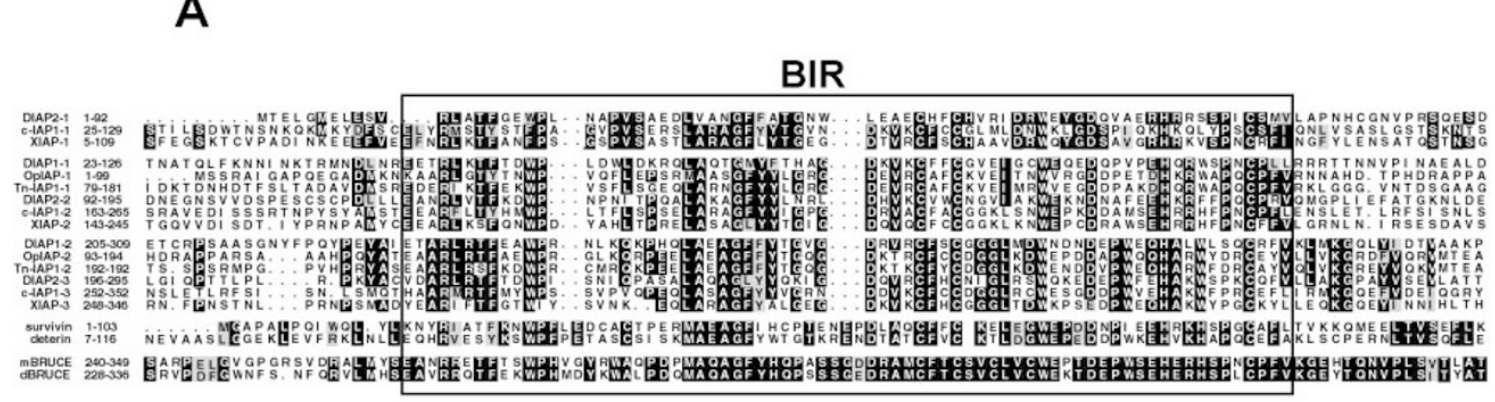

B

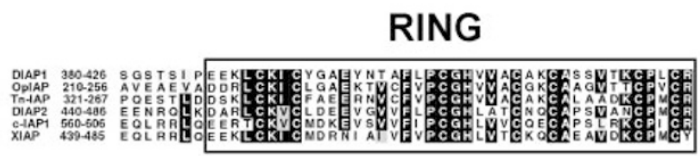

Figure 4 Multiple alignments of the BIR and RING domains of selected IAPs. (A) BIR domains and surrounding sequences for a select group of BIR-containing proteins. The alignments are grouped so as to maximize the alignment among members of each group. The N-terminal BIRs of the three BIR IAPs are aligned together. The N-terminal BIRs of the two BIR IAPs are aligned with the second BIR of the three BIR IAPs. The C-terminal BIRs of the two and three BIR IAPs are aligned together. Deterin and Survivin are aligned together, as are mBRUCE and dBRUCE. Note that the C-terminal BIRs show several regions of similarity within, as well as N- and C-terminal to the BIR domain. The BIR domains of Survivin and Deterin, and mBRUCE and dBRUCE, have several sequence insertions within the BIR. The BRUCE BIRs are much more homologous to each other than to other equally evolutionarily distant BIRs. Alignments were carried out using ClustalW. Residues were boxed in black for the top three groups if two out of three or four out of six residues were identical, respectively. (B) Multiple alignments of RING domains for the BIR-containing proteins shown in (A). Alignments were carried out as above 
interactions with other apoptosis inducers, including Reaper, Hid and Grim. Mutagenesis experiments support the proposition that Drosophila and viral IAPs promote cell survival through multiple mechanisms. These mechanisms include caspase inhibition, but also probably involve other protein-protein interactions that may lead to either protein sequestration, modification or degradation. A version of DIAP1 that lacks the RING finger (start-G381) is sufficient to inhibit cell death in response to multiple stimuli in the fly eye. ${ }^{16}$ This fragment is also able to inhibit caspase-dependent yeast cell death, though less well than the wild-type protein (CJ Hawkins, unpublished). These observations argue that the RING finger is not required for DIAP1 to inhibit caspase activation or activity, but leave open the question of whether the RING promotes DIAP1's function as a caspase inhibitor and/or promotes other caspase modifications, or caspase degradation. The DIAP1 BIR probably has little if any function in isolation since a DIAP1 mutation, th5, that terminates within BIR2 (W273-stop), acts as a strong loss of function mutation in the embryo, in the eye-based dominant modifier assay, and when overexpressed. ${ }^{20-22}$ The DIAP1 BIR2 and surrounding $\mathrm{N}$ - and C-terminal linker sequences (T177-S341) are sufficient to bind the DRONC prodomain. ${ }^{70}$ Further $\mathrm{N}$ terminal deletions of DIAP1 suggest that T177-P204 are also not required for this interaction. It is not known, however, if the T177-S341 fragment is sufficient to inhibit DRONC activation or the activity of other Drosophila caspases. Evidence that DIAP1 BIR2 and surrounding sequences may be sufficient to inhibit caspase activation/activity comes from the observation that a protein consisting of the DIAP1 BIR2 and flanking sequences (P97-S342) is able to inhibit drICEdependent cell death in lepidopteran cells. ${ }^{47}$ However, the caspase targets have not been identified. Interestingly, this same region of DIAP1 (P97-S342) is sufficient to bind Hid in lepidopteran cells, and to inhibit Hid-dependent cell death. ${ }^{49}$ However, interactions between Hid and DIAP1 are likely to be more complex in the context of full length DIAP1because mutations in the DIAP1 BIR1 (G88S) also lead to a decrease in Hid binding. ${ }^{21}$ The Op-IAP region equivalent to the region surrounding DIAP1 BIR2 (R95-D199) also binds Hid and blocks Hid-dependent cell death. A series of point mutations and deletions throughout this region has identified one short sequence (Q174-A190) that is required for Hid binding. ${ }^{49} \mathrm{~A}$ number of residues within this sequence are found following other C-terminal BIR repeats in IAPs that inhibit apoptosis, including C-IAP1 (Figure 4). The structure of the c-IAP1 BIR3 contains this $\mathrm{C}$-terminal extension and shows that a number of residues within this region that are conserved among $\mathrm{C}$ terminal BIRs interact with the c-IAP1 BIR core. ${ }^{95}$ It will be interesting to characterize the consequences of altering the equivalent residues in DIAP1 for their effects on Hid binding. It will also be interesting to see if mutation of these residues in XIAP, c-IAP1 or C-IAP2 alters their ability to bind Smac/ DIABLO, and to inhibit cell death. Mutations of conserved residues within Op-IAP BIR2 itself (R114A, C148A, H168A) result in a protein that does not block Hid-dependent cell death, but does still bind Hid, suggesting that simple binding of Hid is insufficient to block its proapoptotic function. However, it may be relevant in this context that Op-IAP oligomerizes, and that intact BIR repeats are required for this interaction. ${ }^{96}$ It will be interesting to see if there is a relationship between BIR2 mutations that fail to block Hiddependent killing, but not binding and those that are required for dimerization. Survivin dimerizes. ${ }^{66,67,97}$ The multimerization state of other IAPs has not been reported.

A number of reports demonstrate that full length Drosophila or baculoviral IAPs are required to effectively block cell deaths due to baculovirus infection, treatment with actinomycin-D, UV irradiation, expression of Doom, or very high levels of $\mathrm{Hid}^{10,46,50,96}$ In some contexts, expression of versions of baculoviral IAPs that lack the RING finger actually promotes cell death. ${ }^{46,96}$ However for other stimuli, including X-ray irradiation or Hid overexpression in the fly eye, or modest levels of Hid expression in lepidopteran cells, versions lacking the C-terminal RING finger have comparable activity to the full length protein, and in some cases show greater efficacy. ${ }^{16,50}$ These observations emphasize the idea that DIAP1 and baculovirus IAPs inhibit cell death using multiple mechanisms. The RING domain is required for cell death inhibition through some pathways, while for others it appears to play no role or to negatively regulate IAP function. Analysis of the phenotypes associated with a number of DIAP1 mutants isolated from dominant modifier screens for enhancers and suppressors of GMR-rpr, GMR-hid, and GMR-grim-dependent cell death points towards a similar conclusion. $^{21,22}$ In particular, this analysis identifies clear differences in the requirements for DIAP1 to inhibit Reaper and Grim-dependent death versus that due to overexpression of Hid. For example, mutation of conserved cysteine residues in the DIAP1 RING (th6B, C412Y and th81.03, $\mathrm{C} 422 \mathrm{Y}$ ), which presumably disrupts its structure and function, results in flies that are suppressed for Hid killing, but that are enhanced for killing by Reaper and Grim (Figure 4). ${ }^{22}$ In contrast a second mutation, thSL (V85M), results in a dramatic suppression of Reaper and Grimdependent death, but has no effect on death due to Hid. One possibility is that this mutation identifies a residue required for DIAP1 to bind Reaper and Grim, but not Hid. Other DIAP1 mutants that act as dominant suppressors of Reaper and Hid-dependent death, and that show decreased DIAP1 binding (th6-3, G88S and th23-4, G269S), have in fact been isolated. ${ }^{21}$ One of these mutations, G269S, occurs in a glycine residue conserved among C-terminal BIR repeats of apoptosis-inhibiting IAPs (Figure 4). However, not all the differences in the ability of DIAP1 mutants to inhibit Reaper, Hid or Grim-dependent cell death can be attributed to changes in DIAP1's ability to bind these proteins. This is illustrated by the th 4 mutation (H283Y). This mutant acts as a loss of function mutation (a death enhancer) for both Reaper and Hid in the eye-based dominant modifier assay, and in terms of its homozygous embryonic phenotype (all cells die). However, it still binds Reaper and Hid with an affinity comparable to that of the wild-type DIAP1. ${ }^{21}$ This suggests that the th4 protein has lost a death preventing function distinct from an ability to bind and titrate Reaper and Hid away from DIAP1-caspase complexes. Interestingly, however, when overexpressed, the th4 protein blocks Hid-dependent death as well as the wild-type protein, but shows essentially no ability to block 
Reaper-dependent death. Why might this be? Mutational analysis of Reaper and Grim argues strongly that these proteins promote apoptosis through multiple pathways. Thus, deletion of the Reaper- or Grim N-terminus, which mediates binding to DIAP1, results in proteins that can still kill. ${ }^{44,49,98}$ In contrast, the results of experiments in lepidopteran cells argue that the $\mathrm{N}$-terminus of Hid is both necessary and sufficient to mediate Hid's proapoptotic function. ${ }^{49}$ This suggests that Hid acts through a more limited set of pathways. One obvious possibility is that the th4 protein lacks the ability to inhibit caspase activity activated downstream of Reaper and Grim functions that promote caspase activation through DIAP1-independent pathways. This scenario would also explain why the th4 protein acts as a dominant enhancer of Hid-dependent death in the eye, and as a loss of function mutant in the embryo: it is unable to inhibit caspase activation/activity occurring downstream of high level Hid expression in the eye, or the activation/activity of caspases present in the early embryo.

In summary, mutational analysis of DIAP1 and baculovirus IAPs demonstrates that these proteins are functionally complex, and shows that there are distinct sequence requirements for inhibition of different death signals. As discussed above, these IAPs may inhibit apoptosis by sequestering apoptosis inducers and/or blocking caspase activation/activity. The RING domain may participate as a structural element in these activities. In addition, it may mediate ubiquitination of bound substrates. Complicating the mutational analysis even further, the RING may regulate (presumably negatively) IAP function through auto-ubiquitination, which may or may not itself be regulated by the presence of bound substrates. Genetic screens provide a powerful approach to identifying functionally important DIAP1 mutations. However, a number of different assays, including binding, caspase activity, ubiquitination, expression level and cellular localization will be needed to turn these mutants into clear mechanistic models of IAP function and regulation.

\section{Where do we go from here?}

It is clear that IAPs regulate cell death through multiple mechanisms. Many act as caspase inhibitors. However for others such as Survivin and NAIP, this has not been shown. They may regulate death through other mechanisms. The finding that some RING-containing IAPs have E3 ubiquitin ligase has opened up a new and exciting area of study. The potential exists for ubiquitination to both positively and negatively regulate IAP function. In addition, it is important to keep in mind that ubiquitination requires the activity of an E2 ubiquitin carrier protein, of which there are a growing number. The ubiquitin pathway is also regulated by the activity of a number of deubiquitinating enzymes. Therefore, it seems likely that new and exciting regulatory circuits involving IAPS and ubiquitination will emerge over the next few years. The study of insect and baculoviral IAPs has led the way in identifying proteins, Reaper, Hid and Grim, that regulate IAP function. These proteins can suppress the ability of IAPs to inhibit caspase activity. However, given the functional complexity of the insect IAPs (and presumably their mammalian counterparts), it is very possible that they alter IAP function in other ways as well. A further characterization of these interactions is likely to lead to new mechanistic insights into IAP function and regulation. Finally, since this article focuses on Drosophila, it is important to point out the potential of Drosophila genetics to uncover new aspects of IAP function. The dominant modifier screen that led to the original identification of DIAP1, and to the isolation of a number of interesting DIAP1 mutants is a powerful tool because it is a function-based screen. There is every reason to believe that further genetic screens for enhancers and suppressors of Reaper, Hid or Grim-dependent cell death will uncover new aspects of IAP function.

\section{Note added in proof}

Several recent reports ${ }^{99,100}$ demonstrate that, as with Reaper, Hid and Grim in Drosophila, Smac/DIABLO promote the activation and activity of multiple caspases by inhibiting IAP function.

\section{Acknowledgments}

Special thanks to $S$ Vernooy for help with the figures as well as comments on the text. This work was supported by grants from a Burroughs Wellcome Fund New Investigator Award in the pharmacological Sciences, the Ellison Medical Foundation, and NIH grant GM057422-01.

\section{References}

1. Clem RJ, Fechneimer M and Miller LK (1991) Prevention of apoptosis by a baculovirus gene during infection of insect cells. Science 254: 1388-1390

2. Clem RJ, Hardwick JM and Miller LK (1996) Anti-apoptotic genes of baculoviruses. Cell Death Differ. 3: 9-16

3. Ekert PG, Silke J and Vaux DL (1999) Caspase inhibitors. Cell Death Differ. 6: 1081-1086

4. Bump NJ, Hackett M, Hugunin M, Seshagiri S, Brady K, Chen P, Ferenz C, Franklin S, Ghayur T, Li P, Licari P, Mankovich J, Shi LF, Greenberg AH, Miller LK and Wong WW (1995) Inhibition of ICE family proteases by baculovirus antiapoptotic protein p35. Science 269: 1885-1888

5. Xue Dand Horvitz HR (1995) Inhibition of the Caenorhabditis eleganscell-death protease CED-3 by a CED-3 cleavage site in baculovirus p35 protein. Nature 377: $248-251$

6. Ayres MD, Howard SC, Kuzio J, Lopez-Ferber M and Possee RD (1994) The complete DNA sequence of Autographa californica nuclear polyhedrosis virus. Virology 202: 586-605

7. Du Q, Lehavi D, Faktor O, Qi Y and Chejanovsky N (1999) Isolation of an apoptosis suppressor gene of the Spodoptera littoralis Nucleopolyhedrovirus. J. Virol. 73: 1278-1285

8. Crook NE, Clem RJ and Miller LK (1993) An apoptosis-inhibiting baculovirus gene with a zinc finger like motif. J. Virol. 67: 2168-2174

9. Birnbaum MJ, Clem RJ and Miller LK (1994) An apoptosis-inhibiting gene from a nuclear polyhedrosis virus encoding a polypeptide with $\mathrm{Cys} / \mathrm{His}$ sequence motifs. J. Virol. 68: 2521-2528

10. Clem RJ and Miller LK (1994) Control of programmed cell death by the baculoviral genes $p 35$ and iap. Mol. Cell. Biol. 14: 5212-5222

11. Freemont PS (2000) Ubiquitination: RING for destruction? Curr. Biol. 10: 8487

12. Uren AG, Coulson EJ and Vaux DL (1998) Conservation of baculovirus inhibitor of apoptosis repeat proteins (BIRPs) in viruses, nematodes, vertebrates and yeasts. Trends Biochem. Sci. 23: 159-162 
13. Deveraux QL and Reed JC (1999) IAP family proteins - suppressors of apoptosis. Genes Dev. 13: 239-252

14. Vernooy SY, Copeland J, Ghaboosi N, Griffin EE, Yoo SJ and Hay BA (2000) Cell death regulation in Drosophila: conservation of mechanism and unique insights. J. Cell Biol. 150: F69-F75

15. LaCasse EC, Baird S, Korneluk RG and MacKenzie AE (1998) The inhibitors of apoptosis (IAPS) and their emerging role in cancer. Oncogene 17: 3247-3259

16. Hay BA, Wassarman DA and Rubin GM (1995) Drosophila homologs of baculovirus inhibitor of apoptosis proteins function to block cell death. Cell 83: $1253-1262$

17. Jones G, Jones D, Zhou L, Steller H and Chu Y (2000) Deterin, a new inhibitor of apoptosis from Drosophila melanogaster. J. Biol. Chem. 275: 22157-22165

18. Huang Q, Deveraux QL, Maeda S, Salvesen GS, Stennicke HR, Hammock BD and Reed JC (2000) Evolutionary conservation of apoptosis mechanisms: Lepidopteran and baculoviral inhibitor of apoptosis proteins are inhibitors of mammalian caspase-9. Proc. Natl. Acad. Sci. USA 97: 1427-1432

19. Seshagiri S, Vucic D, Lee J and Dixit VM (1999) Baculovirus-based genetic screen for antiapoptotic genes identifies a novel IAP. J. Biol. Chem. 274: 36769-36773

20. Wang SL, Hawkins CJ, Yoo SJ, Muller HA and Hay BA (1999) The Drosophila caspase inhibitor DIAP1 is essential for cell survival and is negatively regulated by HID. Cell 98: $453-463$

21. Goyal L, McCall K, Agapite J, Hartwieg E and Steller H (2000) Induction of apoptosis by Drosophila reaper, hidand grim through inhibition of IAP function. EMBO J. 19: 589-597

22. Lisi S, Mazzon L and White W (2000) Diverse domains of THREAD/DIAP1 are required to inhibit apoptosis induced by REAPER and HID in Drosophila. Genetics 154: 669-678

23. Clem RJ and Duckett CS (1997) The iap genes: unique arbitors of cell death Trends Cell Biol. 7: 337-339

24. Fraser AG, James C, Evan GI and Hengartner MO (1999) Caenorhabditis elegans inhibitor of apoptosis protein (IAP) homologue BIR-1 plays a conserved role in cytokinesis. Curr. Biol. 9: 292-301

25. Uren AG, Beilharz T, O'Connell MJ, Bugg SJ, van Driel R, Vaux DL and Lithgow $\mathrm{T}$ (1999) Role for yeast inhibitor of apoptosis (IAP)-like proteins in cell division Proc. Natl. Acad. Sci. USA 96: 10170-10175

26. Rajagopalan S and Balasubramanian MK (1999) S-pombe Pbh1p: an inhibitor of apoptosis domain containing protein is essential for chromosome segregation. FEBS Letters 460: 187-190

27. Yoon HJ and Carbon J (1999) Participation of BIR1p, a member of the inhibitor of apoptosis family, in yeast chromosome segregation events. Proc. Natl. Acad. Sci. USA 96: 13208-13213

28. Li F, Flanary PL, Altieri DC and Dohlman HG (2000) Cell division regulation by BIR1, a member of the inhibitor of apoptosis family in yeast. J. Biol. Chem. 275 6707-6711

29. Li F, Ambrosini G, Chu EY, Plescia J, Tognin S, Marchisio PC and Altieri DC (1998) Control of apoptosis and mitotic spindle checkpoint by survivin. Nature 396: $580-584$

30. Li F, Ackermann EJ, Bennett CF, Rothermel AL, Plescia J, Tognin S, Villa A Marchisio PC and Altieri DC (1999) Pleiotropic cell-division defects and apoptosis induced by interference with survivin function. Nature Cell Biol. 1: 461-466

31. White K, Grether ME, Abrams JM, Young L, Farrell K and Steller H (1994) Genetic control of programmed cell death in Drosophila. Science 264: 677 683

32. Grether ME, Abrams JM, Agapite J, White K and Steller H (1995) The head involution defectivegene of Drosophila melanogasterfunctions in programmed cell death. Genes Dev. 9: 1694-1708

33. Chen P, Nordstrom W, Gish B and Abrams JM (1996) grim, a novel cell death gene in Drosophila. Genes Dev. 10: 1773-1782

34. Pronk GJ, Ramer K, Amiri P and Williams LT (1996) Requirement of an ICE-like protease for induction of apoptosis and ceramide generation by REAPER. Science 271: $808-810$

35. White K, Tahaoglu E and Steller H (1996) Cell killing by the Drosophila gene reaper. Science 271: 805-807

36. Abrams JM (1999) An emerging blueprint for apoptosis in Drosophila. Trends Cell Biol. 9: 435-440

37. Bangs $P$ and White $K(2000)$ Regulation and execution of apoptosis during Drosophila development. Developmental Dynamics 218: 68-79
38. Thomas BI and Wassarman DA (1999) A fly's eye view of biology. Trends Genetics 15: 184-190

39. Hay BA, Wolff T and Rubin GM (1994) Expression of baculovirus P35 prevents cell death in Drosophila. Development 120: 2121-2129

40. Hay BA, Maile R and Rubin GM (1997) P element insertion-dependent gene activation in the Drosophila eye. Proc. Natl. Acad. Sci. USA 94: 5195-5200

41. Duckett CS, Nava VE, Gedrich RW, Clem RJ, Van Dongen JL, Gilfillan MC, Shiels H, Hardwick JM and Thompson CB (1996) A conserved family of cellular genes related to the baculovirus iap gene and encoding apoptosis inhibitors. EMBO J. 15: 2685-2694

42. Liston P, Roy N, Tamai K, Lefebvre C, Baird S, Cherton-Horvat G, Farahani R, McLean M, Ikeda JE, MacKenzie A and Korneluk RG (1996) Suppression of apoptosis in mammalian cells by NAIP and a related family of IAP genes. Nature 379: $349-353$

43. Uren AG, Pakusch M, Hawkins CJ, Puls KL and Vaux DL (1996) Cloning and expression of apoptosis inhibitory protein homologs that function to inhibit apoptosis and/or bind tumor necrosis factor receptor-associated factors. Proc Natl. Acad. Sci. USA 93: 4974-4978

44. Wing JP, Zhou L, Schwartz LM and Nambu JR (1998) Distinct cell killing properties of the Drosophila reaper, head involution defective, and grim genes. Cell Death Differ. 5: 930-939

45. Bergmann A, Agapite J, McCall Kand Steller H (1998) The Drosophilagene hid is a direct molecular target of Ras-dependent survival signaling. Cell 95: $331-$ 341

46. Harvey AJ, Soliman H, Kaiser WJ and Miller LK (1997) Anti-and proapoptotic activities of baculovirus and Drosophila IAPs in an insect cell line. Cell Death Differ. 4: 733-744

47. KaiserWJ, Vucic D and Miller LK(1998) The Drosophilainhibitor of apoptosis DIAP1 suppresses cell death induced by the caspase drICE. FEBS Lett. 440: $243-248$

48. Vucic D, KaiserWJ, Harvey AJ and Miller LK (1997) Inhibition of reaper-induced apoptosis by interaction with inhibitor of apoptosis proteins (IAPS). Proc. Natl. Acad. Sci. USA 94: 10183-10188

49. Vucic D, Kaiser WJ and Miller LK (1998) Inhibitor of apoptosis proteins physically interact with and block apoptosis induced by Drosophilaproteins HID and GRIM. Mol. Cell. Biol. 18: 3300-3309

50. Vucic D, KaiserWJ and MillerLK (1998)A mutational analysis of the baculovirus inhibitor of apoptosis Op-IAP. J. Biol. Chem. 273: 33915-33921

51. Hawkins CJ, Ekert PG, Uren AG, Holmgren SP and Vaux DL (1998) Antiapoptotic potential of insect cellular and viral IAPs in mammalian cells. Cell Death Differ. 5: 569-576

52. Foley Kand Cooley L (1998) Apoptosis in late stage Drosophilanurse cells does not require genes within the $\mathrm{H} 99$ deficiency. Development 125: 1075-1082

53. Jiang CA, Lamblin AFJ, Steller H and Thummel CS (2000) A steroid-triggered transcriptional hierarchy controls salivary gland cell death during Drosophila metamorphosis. Mol. Cell 5: 445-455

54. Hauser HP, Bardroff M, Pyrowolakis G and Jentsch S (1998) A giant ubiquitinconjugating enzyme related to IAP apoptosis inhibitors. J. Cell Biol. 141:14151422

55. Deveraux QL, Takahashi R, Salvesen GS and Reed JC (1997) X-linked IAP is a direct inhibitor of cell death proteases. Nature 388: $300-304$

56. Roy N, Deveraux QL, Takahashi R, Salvesen GS and Reed JC (1997) The cIAP-1 and C-IAP-2 proteins are direct inhibitors of specific caspases. EMBO J. 16: $6914-6925$

57. Deveraux QL, Roy N, Stennicke HR, Van Arsdale T, Zhou Q, Srinivasula SM Alnemri ES, Salvesen GS and Reed JC (1998) IAPs block apoptotic events induced by caspase- 8 and cytochrome $c$ by direct inhibition of distinct caspases. EMBO J. 17: 2215-2223

58. Deveraux QL, Leo E, Stennicke HR, Welsh K, Salvesen GS and Reed JC (1999) Cleavage of human inhibitor of apoptosis protein XIAP results in fragments with distinct specificities for caspases. EMBO J. 18: 5242-5251

59. Xu DG, Crocker SJ, Doucet JP, StJean M, Tamai K, Hakim AM and Ikeda JE (1997) Elevation of neuronal expression of NAIP reduces ischemic damage in the rat hippocampus. Nat. Med. 3: 997-1004

60. Simons M, Beinroth S, Gleichmann M, Liston P, Korneluk RG, MacKenzie AE Bahr M, Klockgether T, Robertson GS, Weller M and Schulz JB (1999) Adenovirus-mediated gene transfer of inhibitors of apoptosis protein delays apoptosis in cerebellar granule neurons. J. Neurochem. 72: 292-301 
61. MercerEA, Korhonen L, Skoglosa Y, Olsson P-A, Kukkonen JP and Lindholm D (2000) NAIP interacts with hippocalcin and protects neurons against calciuminduced cell death through caspase-3 dependent and -independent pathways. EMBO J. 19: 3597-3607

62. Hofmann K(1999) The modularnature of apoptotic signaling proteins. Cell. Mol. Life Sci. 55: 1113-1128

63. Reed JC and Reed SI (1999) Survivin' cell-separation anxiety. Nat. Cell Biol. 1 : E199-E200

64. Tamm I, Wang Y, Sausville E, Scudiero DA, Vigna N, Oltersdorf T and Reed JC (1998) IAP-family protein survivin inhibits caspase activity and apoptosis induced by Fas (CD95), Bax, caspases, and anticancer drugs. Cancer Res. 58: $5315-5320$

65. Kobayashi K, Hatano M, Otaki M, Ogasawara T and Tokuhisa T (1999) Expression of a murine homologue of the inhibitor of apoptosis protein is related to cell proliferation. Proc. Natl. Acad. Sci. USA 96: 1457-1462

66. Verdecia MA, Huang H-k, Dutil E, Kaiser DA, Hunter T and Noel JP (2000) Structure of the human anti-apoptotic protein survivin reveals a dimeric arrangement. Nat. Struct. Biol. 7: 602-608

67. Muchmore SW, Chen J, Jakob C, Zakula D, MatayoshiED, WuW, Zhang H, LiF, $\mathrm{Ng} \mathrm{S-C}$ and Altieri DC (2000) Crystal structure and mutagenic analysis of the inhibitor-of-apoptosis protein Survivin. Mol. Cell 6: 173-182

68. Hawkins CJ, Wang SL and Hay BA (1999)A cloning method to identify caspases and their regulators in yeast: identification of Drosophila IAP1 as an inhibitor of the Drosophila caspase DCP-1. Proc. Natl. Acad. Sci. USA 96: 2885-2890

69. Hawkins CJ, Yoo SJ, Peterson EP, Wang SL, Vernooy SY and Hay BA (2000) The Drosopohila caspase DRONC is a glutamate/aspartate protease whose activity is regulated by DIAP1, HID and GRIM. J. Biol. Chem. 275: 2708427093

70. Meier P, Silke J, Leevers SJ and Evan GI (2000) The Drosophila caspase DRONC is regulated by DIAP1. EMBO J. 19: 598-611

71. Budihardjo I, Oliver H, Lutter M, Luo X and Wang X (1999) Biochemical pathways of caspase activation during apoptosis. Annu. Rev. Cell Biol. 15: $269-290$

72. Dorstyn L, Colussi PA, Quinn LM, Richardson H and Kumar S (1999) DRONC, an ecdysone-inducible Drosophila caspase. Proc. Natl. Acad. Sci. USA 96: 4307-4312

73. Kanuka H, Sawamoto K, Inohara N, Matsuno K, Okano H and Miura M (1999) Controll of the cell death pathway by Dapaf-1, a Drosophila Apaf-1/CED-4related caspase activator. Mol. Cell 4: 757-769

74. Manji GA, Hozak RR, LaCount DJ and Friesen PD (1997) Baculovirus inhibitor of apoptosis functions at or upstream of the apoptotic suppressor P35 to prevent programmed cell death. J. Virol. 71: 4509-4516

75. Seshagiri S and Miller LK (1997) Baculovirus inhibitors of apoptosis (IAPs) block activation of Sf-caspase-1. Proc. Natl. Acad. Sci. USA 94: 13606-13611

76. LaCount DJ, Hanson SF, Schneider CL and Friesen PD (2000) Caspase inhibitor and inhibitor of apoptosis Op-IAP block in vivo proteolytic activation of an effector caspase at different steps. J. Biol. Chem. 275: 15657-15664

77. Harvey AJ, Bidwai AP and Miller LK (1997) Doom, a product of the Drosophila $\bmod (\mathrm{mdg} 4)$ gene, induces apoptosis and binds to baculovirus inhibitor-ofapoptosis proteins. Mol. Cell Biol. 17: 2835-2843

78. Oeda E, Oka Y, Miyazono K and Kawabata M (1998) Interaction of Drosophila inhibitors of apoptosis with Thick Veins, a type I serine/threonine kinase receptor for Decapentaplegic. J. Biol. Chem. 273: 9353-9356

79. McCarthy JV and Dixit VM (1998) Apoptosis induced by Drosophila Reaper and Grim in a Human system. J. Biol. Chem. 273: 24009-24015

80. Du C, Fang M, Li Y, Li L and Wang X (2000) Smac, a mitochondrial protein that promotes cytochrome c-dependent caspase activation by eliminating IAP inhibition. Cell 102: 33-42

81. Verhagen AM, Ekert PG, Pakusch M, Silke J, Connolly LM, Reid GE, Moritz RL, Simpson RJ and Vaux DL (2000) Identification of DIABLO, a mammalian protein that promotes apoptosis by binding to and antagonizing IAP proteins. Cell 102: $43-53$
82. Kurada P and White K (1998) Ras promotes cell survival in Drosophila melanogaster by downregulating hid expression. Cell 95: 319-329

83. Avdonin V, Kasuya J, Ciorba MA, Kaplan B, Hoshi T and Iverson L (1998) Apoptotic proteins Reaper and Grim induce stable inactivation in voltage-gated K+ channels. Proc. Natl. Acad. Sci. USA 95: 11703-11708

84. Thress K, Evans EK and Kornbluth S (1999) Reaper-induced dissociation of a scythe-sequestered cytochrome c- releasing activity. EMBO J. 18:5486-5493

85. Hershko A and Ciechanover A (1998) The ubiquitin system. Annu. Rev. Biochem. 67: 425-479

86. Deshaies RJ (1999) SCF and cullin/RING H2-based ubiquitin ligases. Annu. Rev. Cell Dev. Biol. 15: 435-467

87. Yang Y, Fang S, Jensen JP, Weissman AM and Ashwell JD (2000) Ubiquitin protein ligase activity of IAPs and their degradation in proteosomes in response to apoptotic stimuli. Science 288: $874-877$

88. Huang H-k, Joazeiro CAP, Bonfoco E, Kamada S, Leverson JD and Hunter T (2000) The inhibitorclAP1, functions as a ubiquitin-protein ligase and promotes in vitro mono-ubiquitination of caspases-3 and -7. J. Biol. Chem. 275: 26661 26664

89. Velculescu VE, Madden SL, Zhang L, Lash AE, Yu J, Rago C, Lal A, Wang CJ, Beaudry GA, Ciriello KM, Cook BP, Dufault MR, Ferguson AT, Gao YH, He TC, Hermeking $\mathrm{H}$, Hiraldo SK, Hwang PM, Lopez MA, Luderer HF, Mathews B, Petroziello JM, Polyak K, Zawel L, Zhang W, Zhang XM, Zhou W, Haluska FG, Jen J, Sukumar S Landes GM, Riggins GJ, Vogelstein B and Kinzler KW (1999) Analysis of human transcriptomes. Nat. Genet. 23: 387-388

90. Suzuki A, Ito T, Kawano H, Hayashida M, Hayasaki Y, Tsutomi Y, Akahane K, Nakano T, Miura M and Shiraki K (2000) Survivin initiates procaspase 3/p21 complex formation as a result of interaction with $\mathrm{Cdk} 4$ to resist Fas-mediated cell death. Oncogene 19: $1346-1353$

91. Guo Mand HayBA (1999) Cell proliferation and apoptosis. Curr. Opin. Cell. Biol. 11: $745-752$

92. Suzuki A, TsutomiY, AkahaneK, Araki T and Miura M(1998) Resistance to Fasmediated apoptosis: activation of caspase 3 is regulated by cell cycle regulator p21WAF1 and IAP gene family ILP. Oncogene 17: 931-939

93. Takahashi R, Deveraux QL, Tamm I, Welsh K, Assa-Munt N, Salvesen GS and Reed JC (1998) A single BIR domain of XIAP sufficient for inhibiting caspases. J. Biol Chem. 273: 7787-7790

94. Sun C, Cai M, Gunasekera AH, Meadows RP, Wang H, Chen J, Zhang H, Wu W, Xu N, Ng SC and Fesik SW (1999) NMR structure and mutagenesis of the inhibitor-of-apoptosis protein XIAP. Nature 401: 818-822

95. Hinds MG, Norton RS, Vaux DL and Day CL (1999) Solution structure of a baculoviral inhibitor of apoptosis (IAP) repeat. Nat. Struct. Biol. 6: 648-651

96. Hozak RE, Manji GA and Friesen PD (2000) The BIR motifs mediate dominant interference and oligomerization of inhibitor of apoptosis Op-IAP. Mol. Cell. Biol. 20: 1877-1885

97. Chantalat L, Skoufias DA, Kleman J-P, Jung B, Diderberg $O$ and Margolis RL (2000) Crystal structure of human Survivin reveals a bow tie-shaped dimer with two unusual $\alpha$-helical extensions. Mol. Cell 6: 183-189

98. Chen P, Lee P, Otto L and Abrams J (1996) Apoptotic activity of REAPER is distinct from signaling by the tumor necrosis factor receptor 1 death domain. J. Biol. Chem. 271: 25735-25737

99. Chai JJ, Du CY, Wu JW, Kyin S, Wang XD and Shi YG (2000) Structural and biochemical basis of apoptotic activation of Smac/DIABLO. Nature 406: $855-$ 862.

100. Srinivasula SM, Datta P, Fan X-J, Fernandez-Alnemri T, Huang Z and Alnemri ES (2000) Molecular determinants of the caspase-promoting activity of Smac/ DIABLO and its role in the Death receptor pathway. J. Biol. Chem. (in press). 